\title{
La Torre de Dánae
}

El objeto es siempre la víctima del sujeto. Todas nuestras tentativas de trascender el espejo de Narciso, de ver más allá de nuestra subjetividad, son fútiles, a menos que recibamos de una potencia externa una vía de escape de nuestro solipsismo. Pero, a pesar de esto, seguimos mirando: tratamos de entender las cosas, interpretarlas -es decir, de encontrar en ellas elementos que corresponden a los de nuestro modo de ser aunque no tengamos ni las cualidades análogas ni la seguridad de que nuestro análisis sea correcto.

Toda traducción, toda la apropiación voluntaria que cometemos cuando invadimos las fronteras de algo fuera de nuestros límites físicos, es un acto de violencia. Y sin embargo, es simultáneamente una invitación: nosotros también queremos ser invadidos, recreados por fuerzas externas. Esse est percipi. Sólo siendo manipulados podemos estar segurós de nuestra existencia. Existimos sólo én la medida en que quedamos enajenados de nuestros modos de ser primitivos: esto nos tranquiliza y nos horroriza. Una absoluta libertad de reificación externa nos desterraría a la inexistencia, y una reificación absoluta nos privaría de identidad. Quizás la autorrealización es posible sólo a través de una especie de fisión binaria: un proceso en que el individuo podria dividirse en dos mitades, observarse, interpretarse y unificarse otra vez.

Estos son los conceptos básicos que encontramos en la obra de Julio Cortázar entre 1946, fecha de su ensayo "La urna griega en la poesía de John Keats", ${ }^{1}$ y 1963, fecha en que publicó Rayuela. ${ }^{2}$ Los attículos de crítica que Cortázar escribió durante los años 40 y los primeros años de la década de los 50 son el producto de un análisis de la tradición li-

1 Julio Cortázar, "La urna griega en la poesia de John Keats," Revista de Estzudios Clásicos, Universidad de Cuyo, Argentina, año II, 49-61 (1946), Pp. 45.91 .

2 Julio Cortázar, Rayuela (Buenos Aires: Sudamericana, 1963). 
teraria en que Cortázar pretendía hallar los rasgos esenciales del investigador en lo investigado. Para Cortázar, la tradición es Proteo: no el dios que, una vez capturado, da consejos, sino el dios que puede asumir la configuración que más agrada a Cortázar. La tradición es también la fuente de Narciso, aunque en este caso la fuente está llena de figuras, y Narciso tiene que buscar su imagen y separarla de otras.

En "Notas sobre la novela contemporánea" (1948) ${ }^{3}$ y "Situación de la novela" (1950), "Cortázar investiga la historia de la novela, no como un historiador de la literatura, sino como un explorador literario, delimitando continentes nuevos. Los dos ensayos tratan de la mise en scéne nóvelesca, del lenguaje en que la novela se presenta al lector, y también del tipo de situación que encuentra el lector al abrir el libro. Los dos ensayos, además, tratan de demostrar la superioridad de una clase de novela sobre otra.

"Notas sobre la novela contemporánea" empieza con algunas ideas generales sobre los varios tipos de lenguaje que se encuentran en las novelas $\mathrm{y}$ otras formas narrativas:

Toda narración comporta el empleo de un lenguaje científico, nominativo, con el que se alterna imbrincándose inextricablemente un lenguaje poético, simbólico, producto intuitivo donde la palabra, la frase, la pausa y el silencio valen trascendentemente a su significación idiomática directa. (241)

El estilo de un novelista, añade Cortázar, depende de cómo mezcla estos dos modos lingüísticos. Pero, recientemente, un modo, el poético, ha tendido a desplazar el otro, el enunciativo. Sigue Cortázar diciendo que es posible analizar la novela investigando su combinación particular de idiomas, que ya se ha hecho esto, pero que este análisis nunca ha intentado formulat una estética de la novela:

Buena parte de la montaña crítica en torno a la novela procede de este desmontaje siempre pródigo en descubrimientos y variedades; lo que no se había denunciado hasta nuestro tiempo $\rightarrow$ en abierta postura antagónica- era la superestructura estética que codificaba, liviana pero inflexiblemente, la arquitectura novelesca.

3 Julio Cortázar, "Notas sobre la novela contemporánea," Realidad, año II, 8 (1948), pp. 240-246.

4 Julio Cortázar, "Situación de la novela," Cutadernos Americanos, año IX, 4 (1950), pp: 294-297. 
Mas he aquí que tal orden ha dejado de merecer la confianza del escritor característico de las tres últimas décadas, e importa mostrar ya como se nos propone en la etapa moderna de la novela el modus vivendi de lo enunciativo y lo poético, para ver con más claridad el brusco desacuerdo interno que estalla en la novela, la ruptura de la alternancia y la "entente cordiale" que el talento novelístico obtenía y empleaba. (243)

El resultado de esta guerra civil lingüística es una nueva estética, la expresión de la edad moderna, la "novela poética":

El nuevo avance del dajmón poético cumplido en nuestro siglo no debe ser entendido sin embargo como un retorno a la indiferenciación entre novelesco y poético que se daba en la tragedia y la narración épica. Aún entonces, y sin claridad preceptiva suficiente, el escritor advertía las diferencias entre la enunciación discursiva y racionalizada, y la expresión poética dramática o lírica. En nuestro tiempo se concibe la obra como una manifestación poética lotal, que abraza simultáneamente formas aparentes como el poema, el teatro, la narración. Hay un estado de intuición para el cual la realidad, sea cual fuere, sólo puede formularse poéticamente, dentro de modos poemáticos, narrativos, dramáticos: y eso porque la realidad, sea cual fuere, sólo se revela poemáticamente. (246)

Sólo en "Situación de la novela" clarifica Cortázar lo que enuncia en la última parte del texto citado arriba. Casi parece como si la primera frase del segundo ensayo fuera una continuación, una elaboración de las posibilidades sugeridas en el primero:

Alguna vez he pensado si la literatura no merecía considerarse una empresa de conquista verbal de la realidad. No por razones de magia, para la cual el nombre de las cosas (el nombre verdadero, oculto, ese que todo escritor busca aunque no lo sepa) otorga la posesión de la cosa misma. (223)

La perspectiva existencialista del ensayo, su insistencia en la influencia personal del artista en la forma de las cosas, lleva a Cortázar más cerca de los problemas de las relaciones que hemos estado examinando aquí, pero él no se interesa tanto en establecer una filosofía - del arte o de la vida - como en distinguir lo "moderno" de lo "anticuado." Esta dis- 
tinción viene acompañada de una demanda ideológica: que la nueva novela se distinga de la antigua no sólo en su lenguaje sino en su actitud hacia la humanidad:

Quiero decir en este punto que la novelística de extrema tensión existencial, de compromiso con lo inmanente humano, es la que señala con más claridad de interrogación de nuestro tiempo. Repito que si la novela clásica relató el mundo del hombre, si la novela del siglo pasado se preguntó gnoseológicamente el cómo del mundo del hombre, esta corriente que nos envuelve hoy busca la respuesta al por qué y al para qué del mundo del hombre. (239-240)

Implícita en la lectura cortazariana de la literatura moderna es una fórmula para ser moderno. El dice que la "novelística de extrema tensión existencial" es el símbolo de nuestra edad, automáticamente sugiriendo que si alguien tratara de escribir en una manera que no poseyera "extrema tensión existencial" estaría escribiendo en una manera anticuada:

Que es asi puede verse en las conclusiones a que llega Cortázar:

Creo que la novela que hoy importa es la que no rehuye la indagación de esa culpa; creo también que su futuro se anuncia ya a través de obras en las que la tiniebla se espesa para que la luz, la pequeña luz que tiembla en ellas, brille mejor y sea reconocida. En plena noche, esa lumbre alcanza a iluminar el tostro de quien la lleva consigo y la protege con su mano. (243)

La "culpa" a que se refiere Cortázar en la primera frase es el sentido de culpa que los personajes de algunas novelas de la época (L'Etranger, The Glass Key, They Shoot Horses, Don't They?) sienten y que nosotros como lectores sentimos, una culpa que lleva a una identificación -no entre el lector y el personaje- sino entre el lector y una serie de dilemas, emociones y reacciones. $Y$ sin embargo, hay algo más que un poco de dogmatismo en la admiración de Cortázar por la nueva novela. Es el espíritu parroquial del iluminado, del hombre que está seguro de que tiene razón, y que, naturalmente, los demás están equivocados. ¿Quiénes son estos "otros"? Habria que suponer que son los escritores de "la novela clásica," la novela del siglo XIX; todos los escritores contemporáneos que no escriben la novela poética, existencial.

Es la última imagen de "Situación de la novela" que nos llama la ațençión. El ensayista acaba de presentar lo que él ve como la nẹceșidạd 
de inmediatez, la necesidad de un estilo "duro" que meta el lector en una clase de situación que éste siempre ha tratado de evitar. Pero, en realidad, lo que tenemos en la misma explicación que nos da Cortázar, es un ícono, una imagen, hasta una alegoría. Es el mito medieval (repetido por Dante) de Virgilio anunciando el cristianismo al mundo tomano, el espíritu prometeico que se inmortaliza llevando la luz al hombre. La tradición que respalda esta imagen es larga, pero ha cobrado nueva vida desde el Romanticismo y con la restauración de ciertos ideales románticos en el existencialismo.

Es, otra vez, la invitación a la interpretación, el deseo de ser absorbido por el otro - con la esperanza de que el intérprete se fundirá con el objeto, que el mensaje del artista precipitará una metamorfosis en el lector, transformándolo en el artista. Este nivel, sin embargo, se queda al fondo, reprimido por el deseo del autor de definir la literatura según sus propios criterios, de organizar el caos del arte contemporáneo en $\mathrm{pO}_{\text {? }}$ los positivos y negativos.

No hay nada único en esto. Es una versión correcta si no original del "yo soy yo y mi circunstancia" de Ortega, la misma actitud que asociamos con el existencialismo del siglo xx. Pero la transformación de esta idea en arte es un proceso que exige nuestra atención, porque la dramatización del proceso representa una fase muy importante de la entelequia intelectual de todos los escritores pos-románticos.

El primer intento importante de Cortázar por presentar narrativamente la problemática relación entre sujeto y objeto, el cuento "Axolotl", s se basa en un rompecabezas:

Hubo un tiempo en que yo pensaba mucho en los axolotl. Iba a verlos al acuario del Jardin des Plantes y me quedaba horas mirándolos, observando su inmovilidad, sus oscuros movimientos. Ahora soy un axolotl. (161)

El proceso parece completo: el uno se transformó en el otro; un circuito fue abierto por una fuerza misteriosa y el sujeto llegó a ser el objeto. Una metamorfosis parece haber ocurrido, pero en realidad no es así. Aun aquí, en este primer párrafo, donde se hacen sentir ecos de la fraseo'o-

5 Julio Cortázar, "Axoloṭl," Bestiațio (Buenos Airẹs: Sudamericana, 1951). 
gía escueta de la "Metamorfosis" de Kafka, la presencia ajena de un tercero se manifiesta. No hay aquí ninguna dialéctica, sólo un truco, el truco del artista, el tercero que puede sugerir el fluir del tiempo, o, si quiere invocar la tradición de la vara mágica de Próspero, hacer que ocurran las cosas.

El relato de Cortázar ha sido, sin embargo, interpretado como si presentara una metamorfosis. René Micha ${ }^{6}$ lo ha llamado una nueva versión de la famosa "Lettre du Voyant," la carta de Rimbaud a Paul Demeny. Micha resume e interpreta "Axolotl" asi:

C'est l'histoire d'un homme qui chaque jour contemple les axolotls au Jardin des Plantes et qui un jour devient axolotl-les axolotls sont des sortes de lézards, leur nom est mexicainn. Le "Je est un Autre" de la Lettre du Voyant trouve ici son application la plus simple: on traverse une vitre, on est ce qu'on voit sans cesser d'être soi-même; cependant cet obstacle transparent est un obstacle absolu, qui interdit la communication s'il ouvre un va-et-vient mystérieux entre la $J e$ et le Je. Cortazar fonde son récit sur une conscience sans mémoire, qui se divise sans se perdre. Le Je est indifféremment l'home et l'axolotl, l'Autre est indifféremment l'homme et l'axolotl. Cependant la Je est aussi celui qui écrit, qui franchit le miroir, qui va de l'un à l'autre, qui à la conscience ajoute un peu de réalité, des lambeaux de mémoire. Voici qu'à cause de ce Je-Auteut, chaque mouvement a un sens, devient lisible: comme la sentence que la machine de Kafka inscrit dans la chair du condamné. Nous sommes l'homme, nous sommes l'axolotl, nous sommes enterrés vivants, nous écrasons notre visage, quel visage? contre l'aquarium. La vitre nous coupe en deux. Nous sommes la bête à deux dos. (315)

La interpretación es muy provocativa, pero está basada en algunos puntos dudosos. Micha aparentemente deriva su concepto de metamorfosis del pasaje siguiente:

Mi cara estaba pegada al vidrio del acuario, mis ojos trataban una vez más de penetrar el misterio de esos ojos de oro sin iris y sin pupila. Veía de muy cerca la cara de un axolotl inmóvil junto al vidrio. Sin transición, sin sorpresa, vi mi cara contra el vidrio, la vi fuera del acuario, la vi del otro lado del vidrio. (166)

"René Micha, "Le je et l'autre chez Julio Cottazar," La Nouvelle Retue Frath. faise, 140 (1964), pp. 314-322. 
En realidad parece que el hombre se ha transformado en axolotl, y sin embargo, si leemos el párrafo siguiente, encontramos algo distinto:

Afuera, mi cara volvía a acercarse al vidrio, veía mi boca de labios apretados por el esfuerzo de comprender a los axolotl. Yo era un axolotl y sabía ahora instantáneamente que ninguna comprensión era posible. El estaba fuera del acuario, su pensamiento era un pensamiento fuera del acuario. Conociéndolo, siendo él mismo, yo era un axolotl y es'aba en mi mundo. El horror venía - lo supe en el mismo momento- de creerme prisionero en un cuerpo de axololtl, transmigrado a él con mi pensamiento de hombre, enterrado vivo en un axolotl, condenado a moverme lúcidamente entre criaturas insensibles. Pero aquello cesó cuando una pata vino a rozarme la cara, cuando moviéndome apenas a un lado vi a un axolotl junto a mí que me miraba, y supe que también él sabía, sin comunicación posible pero tan claramente. O yo estaba también en él, o todos nosotros pensábamos como un hombre, incapaces de expresión, limitados al resplandor dorado de nuestros ojos que miraban la cara del hombre pegada al acuario. (167)

El axolotl, entonces, fue siempre un axolotl, el hombre fue siempre un hombre, y la conexión entre ellos existió sólo temporariamente y sólo en la conciencia del animal -al menos ésta es la única visión que nos da el artista. Esto se confirma en el último párrafo del cuento, donde el axolotl comenta su experiencia y su relación con el hombte:

Se me ocurre que al principio continuamos comunicados, que él se sentía más que nunca unido al misterio que lo obsesionaba. Pero los puentes están cortados entre él y yo, porque lo que era su obsesión es ahora un axolotl, ajeno a su vida de hombre. Creo que al principio yo era capaz de volver en cierto modo a él - ah, sólo en cierto modo-y manener alerta su deseo de conocernos mejor. Ahora soy definitivamente un axolotl, y si pienso como un hombre es sólo porque todo axolotl piensa como un hombre dentro de su imagen de piedra rosa. Me parece que de todo esto alcancé a comunicarle algo en los primeros dias, cuando yo era todavía él. $Y$ en esta soledad final, a la que él ya no vuelve, me consuela pensar que acaso va a escribir sobre nosotros. creyendo imaginar un cuento va a escribir todo esto sobre los axolotl. (168) 
El chiste, como simpre, está a expensas del lector. Lo que pudiera haberse tomado por una complicada mezcla de mentes, una confusión de sujeto † objeto, es en realidad una ficción, el desarrollo de la pregunta: "¿Qué pasaria si...?" Pero dentro de la ficción, ¿qué ha pasado?

Como resultado de los "puentes" que el narrador ambiguo dice que se establecieron, la conciencia del axolotl (no un animal real sino el producto de la imaginación) podía visitar la mente del observador, ver las cosas desde su perspectiva y en alguna manera comunicarse con él. La realidad de aquella perspectiva vino a ser tan absoluta para el visitante que su concepto de la realidad se fundió con ella, y cuando fue "devuelto" a su mundo de axolotl, momentáneamente sentía como si fuera un hombre cuya mente había sido trasplantada en el cuerpo de un axolotl. La parábola china, repetida por Borges, del filósofo que sueña que es una mariposa que se despierta y se pregunta si es una mariposa soñando que es un filósofo puede servir de glosa a la situación del axolotl, aunque la experiencia de éste es más complicada.

Al final del relato se nos informa explícitamente que lo que hemos leído es una ficción, que quizás se basa en una situación real en que la fantasía del autor ha meditado. El problema filosófico de interpretación - de epistemología parece reducido en importancia, desplazado por el problema puramente estético de la representación de lo irreal. Es verdad que el contexto dramático de este problema está dentro del problema de la relación entre sujeto $\mathrm{y}$ objeto, pero hasta esto se presenta en una manera irónica. No sabemos lo que el hombre sentia (a menos que simplifiquemos el asunto haciendo del hombre del relato el artista y suponiendo veracidad de su. parte); no sabemos qué importancia tenía esta experiencia para él; de él no sabemos nada.

Este es el tema del cuento: la impenetrabilidad del individuo. ¿Por qué otra razón para presentar el cuento desde el punto de vista del axolotl? ¿Quién, además del artista, puede hacer hablar un axolotl? ¿Quién si no el artista puede transformar su público en axolotls? -a menos que presumamos que nosotros también estamos teniendo una experiencia como la del hombre que entró un día de primavera en el Jardin des Plantes.

Un antecedente posible, uno que he sugerido en otra parte, ${ }^{7}$ para la experiencia relatada en "Axolotl" es la "capacidad negativa"'s de John

7 Alfred J. Mac Adam, El individuo y el otro (Buenos Aires: Ediciones La Librería, 1971), pp. 25-26.

s Ver: John Keats, The Letters of John Keats, ed. Maurice Buxton Forman, 4th ed. (Iondon: Oxford Univ. Press, 1952), la carta a Benjamin Bailey, no. 31, sábado, 22 de noviembre de 1817 y la carta a Richard Woodhouse, no, 93, miệrcolẹs 27 dẹ octubte dẹ 1818 , pp. $66-69$, pp. 226-?228, 
Keats. Ahora me parece menos cierto que la situación de "Axolotl" sea idéntica a la falta de personalidad del poeta, su existir como una función de otras personas, realidades o circunstancias. En "La urna griega en la poesía de John Keats," Cortázar estudia el Romanticismo inglés y su relación con el mundo clásico, poniendo un énfasis particular en Keats. En su ensayo menciona la fusión del poeta con la naturaleza, el famoso momento en que Keats muestra cómo puede participar en la vida de un pájaro:

Para esa proyección sentimental contaba Keats con la admirable - y angustiosa- característica de todo poeta: la de ser otro, estar siempre en y desde otra cosa. Su conciencia de esa ubicuidad disolvente -que abre al poeta los accesos del ser y le permita retornar con el poema a modo de diario de viaje- se revela en los siguientes párrafos de una carta: (Cortázar cita la carta a continuación). (65)

El comentario de Cortázar revela el origen de su relato, y su análisis de Keats se transforma en otro viaje de auto-descubrimiento por parte de él.

La segunda etapa de esta operación efectuada por Cortázar es La utilización de la crítica como materia prina del arte. Kents sentía aqueIlas ausencias, aquellas participaciones en lo otro; Cortázar utiliza aquella experiencia. Este acto es también un modo de participar en la realidad de otra persona, aunque es la misma clase de apropriación realizada por el actor cuando "es" Hamlet. Es decir, Cortázar construye un escenatio sobre los restos, la versión escrita post fadto, de la experiencia vital de Keats. Esto explica quizás porqué Cortázar tiene que orientar su cuento hacia lo fantástico, lo irreal. No puede tratarlo sino de una manera abstracta, $y$ no puede mantener siquiera la continuidad de su dramatización. La ficción tiene que "abrirse" al final; el artista, como un actor después de la función, tiene que revelarse en la luz real otra vez, su maquillaje y. su traje obviamente falsos. Lo que experimentó Kats fue algo vivido; Cortázar lo transforma en máscara, en persona.

El tipo de enajenación de que habla Rimbaud en la carta a Paul Demeny no se parece a la experiencia del hombre en "Axolotl":

On n'a jamais bien jugé le romantisme. Qui l'aurait jugé, Les Critiques! Les Romantiques? qui prouvent si bien que la chanson est si peu souvent l'oeuvre, c'est-à-dire la pensée chantée et comprise du chanteur. Car JE est un autre. Si le cuivre s'éveille clairon, il n'y a rien de sa faute. Cela m'est évident: j'assiste à l'éclosion de 
ma pensée: je la regarde, je l'écoute: je lance un coup d'archet: la symphonie fait son remuement dans les profondeurs, ou vient d'un bond sur la scène. ${ }^{9}$

Rimbaud, en la sección de su carta en que aparece este pasaje, está hablando del "yo" y de la auto-decepción que permite al egoismo creer que es poético. El producto de la mente es la poesía, pero la mnte en sí no es poética. El sujeto siempre mutila el objeto: pero para Cortázar la tragedia es que ninguna de sus dos figuras puede ser la otra. Si el observador pudiera observarse, podría confirmar su propia existencia: Narciso se ve a sí mismo en el agua, pero nadie le mira a él. Cortázar quiere que el intercambio sea mutuo, idéntico y completo.

Narciso tiene que ser substituido por los Gemelos, pero aun esta reducción iconográfica tiene que incluir testricciones. Los Gemelos (el individuo partido en dos) tradicionalmente han representado alter egos: Balin y Balan, Jekyll y Hyde, Cuerpo y Alma. Las dualidades, como los héroes- traidores de Borges (de "La forma de la espada", por ejemplo), no son el concepto en que medita Cortázar mientras escribe sus cuentos y romances. ${ }^{10}$ El fenómeno de la metempsicosis que aparece en muchas de sus obras no es una representación alegórica de los lados positivo y negativo de la naturaleza humana; tampoco es una representación de la esquizofrenia. Es un deseo de descubrir nexos entre objetos distintos y distantes, es la teoría de las "figuras", 11 una necesidad de crear líneas de comunicación entre elementos aislados.

\section{III}

La búsqueda más patente de unidad en la literatura de Cortázar es la de Horacio Oliveira en Rayuela. Esta obra, en su aspecto novelesco, tiene la estructura de una búsqueda tradicional, aunque no es una búsqueda física del Gral o del Velloncino de Oro. En este segundo sentido, Rayuela contiene poco movimiento significativo. Es decir, aunque hay muchos cambios de escena - Horacio vaga por París, vuelve a Buenos Aires- Ia experiencia final del protagonista no se relaciona con distan-

9 Jean-Nicolas Arthur Rimbaud, "A Paul Demeny, 15 de mayo de 1871," Oeuvres, ed. Suzanne Bernard (Paris: Garnier, 1960), p. 345.

Io Northrop Frye, "Romance", en "Glossary", Anatomy of Criticism: Foup Essays (Princeton: Princeton Univ. Press, 1957), p. 367.

11 Luis Harss, "Julio Cortázar o la cachetada metafísica", Los nuestros (Buenos Aires: Sudamericana, 1966), p. 278. 
cias y etapas, como ocurre, por ejemplo, en El asno de oro o en la Divina commedia. En estas obras la transformación o purificación del héroe se mide en el espacio, y cada paso que da lo lleva más cerca de su meta. El viaje de Oliveira es el de los místicos, o tal vez de San Agustín: él espera una comunicación directa con lo otro, una seña o quizás una comunión. Viaja, pero no recibe la gracia sólo porque ha atravesado una distancia precisa.

El camino de Oliveira está lleno de pistas falsas: los dobles. Ossip Gregorovius, que sigue el camino intelectual a la iluminación, representa una posibilidad que Oliveira rechaza; la Maga es una posibilidad que ha sido negada a Oliveira. Los dos son polos, uno el polo negativo, el fracaso del individuo que pretende ganar la gracia por su cuenta, imposible en el mundo cortazariano, y la otra, el polo positivo, imposible de alcanzar sin ayuda externa. El tercer doble, Traveler, es al principio otro posible Becerro de Oro, otra imagen que Oliveira tiene que destruir en el crisol de la imaginación creativa. La imagen devuelta por el espejo Traveler tiene que ser transmutada por medio de un rito mágico si de veras el protagonista ha de ganar la salvación. Sólo la transformación de la materia impura, Oliveira y su doble, en materia noble a través del arte puede transformar la voluntad de unidad de Oliveira en un hecho -un hecho, naturalmente, ficticio, mental.

Pero, ¿qué es lo que Oliveita alcanza o no en el misterioso Capítulo 56? ¿Quién le concede o le niega la gracia? Tal vez alcanza la unidad: quizás él se "ve" a sí mismo desde dos perspectivas. Sería entonces posible definirlo como otro Cronos triunfante que ha destruido a su padre para ser su padre. La confirmación más explícita de existencia sería una situación en que uno reemplazaría a su origen paterno. El padre es el creador; reemplazarlo es serlo. (Es interesante notar que en las otras obras de Cortázar no hay padres, situaciones edípicas, oportunidades artísticas para la resolución de problemas relacionados con el complejo edípico, excepto en el nivel místico que encontramos en Rayuela.)

Los místicos afirman que sus experiencias, sus uniones con la divinidad, son reales, no imaginarias. ¿Hasta qué punto en la vida real (nuestras vidas) quiere Cortázar extender su ficción? ¿Está Cortázar utilizando estructuras religiosas para combatir la lógica? Según la tesis de M. H. Abrams, ${ }^{12}$ los románticos:

trataron de conservar de su tradición religiosa el panorama que ésta postulaba de la historia humana ỵ el destino, los paradigmas

12 M. H. Abrams, Natural Supernaturalism, Tradition and Revolution in. Ro. mantic Literature (New Yotk: Norton, 1971), p. 66. 
de la experiencia, y los valores básicos, reconstituyéndolos de tal manera que serían intelectualmente aceptables y emocionalmente relevantes, al menos por el momento. (66)

Y si es cierto que Cortázar, como los románticos, sigue una trayectoria cristiana para la vida de su protagonista, ¿debemos concluir que Rayue. la es una versión de la Confesiones de San Agustín? ¿Serán la "Ciudad" - la: "zona" de que habla el narrador de 62 modelo para armar's3 especies de una civitas Dei laica? Las respuestas a estas preguntas tendrían que ser afirmativas si supusiéramos que el autor, consecuente con lo que había dicho en sus ensayos de los años 40 y 50, de veras quiere cambiar a sus lectores, enfrentarlos con un texto que contenga una filosofia-en-acción, una vida de santo.

La trayectoria de la novela dentro de Rayuela es agustiniana: tenemos un rechazo de los modos intelectuales de llegar a la gracia (Ossip), una gracia distinta de la dada al santo (la Maga); hay una peregtinación (de París a Buenos Aires) que en sí no significa nada, pero que es una etapa misteriosamente importante en el proceso que llevará al protagonista a sentir que algo le va a ocurrir; y finalmente hay el libro, el texto que Oliveira está escribiendo al final del Capítulo 3. A través de este documento, que se asemeja en esto a las Confesiones de San Agustín y a la Divina commedia, el lector se pone en contacto con una posibilidad espiritual, aunque no se puede saber dónde termina la ficción y dónde empieza la vida.

En 62, las resonancias agustinianas se expresan en la forma de un locus: la "zona" o la "Ciudad" que existen, como la ecclesia o el nosotros de que habla San Agustín. ${ }^{14}$ No son necesariamente cosas concretas; son una comunidad tangenical al mundo sin-comunidad, $y$ constituyen una estructura mental-sentimental que alivia la enajenación y el aislamiento individuales. Los ciudadanos privilegiados de esta ciudad han recibido una especie de gracia; son, de alguna manera, gente escogida. Cómo llegaton a merecer este don no se explica, pero el autor tampoco insiste en dar un significado metafísico muy fuerte a la comunidad.

Rayuela, en cambio, resulta una nueva Divina commedia, una ficción que contiene la verdad, un texto con pretensiones bíblicas. En Rayuela, Cortázar asume la persona de un santo; criticar su libro entonces es efec-

13 Julio Cortázar, 62 modelo para armar (Buenos Aires, Sudamericana, 1968).

14 F. Edward Cranz, "De Civitate Dei, XV, 2 and Augustine's Idea of the Christian Society," Speculum, 25 (1950), pp. 215.225, republicado en: Augustine, a Collection of Critical Essays, ed. R. A. Markus (New York: Doubleday, 1972), ver: notas 3 y 21 . 
tuar una especie de exégesis de un texto sagrado. Sólo falta un elemento: Dios. Pero está presente en Rayuela, y en todos sus libros, una fuerza que precipita los intercámbios metempsicóticos, que da a Oliveira intuiciones sobre lo que la unidad puede ser, el poder que frustra a Johnny Carter, en "El perseguidor", con experiencias de ubicuidad temporal. ¿Cómo será este Dios cortazariano? No tiene imagen, pero sí tiene ya una teología: una clase de calvinismo radical que define la vida como una espera, penetrada o por una epifanía - lo que se denomina ubicuidad o unidad en las otras obras, pero que resulta ser la misma cosa- o por la muerte.

Como los místicos, Cortåzar canta ausencias. El acto de escribir llena este espacio, teóricamente porque nos enfrenta con hechos mágicos, como el de "Axolotl", y prácticamente porque afirma lo efímero, el autor mismo mano a mano con la inexistencia, es decir, el tiempo, la enajenación absoluta. Es de la historia, la historia literaria, de donde btota Cortázar, y es la historia a donde tendrá que volver. Sólo la tradición lo salvará, aunque el Cortázar vivo, como el "yo" de "Borges y yo", esperará su iluminación. Su metafísica no llevará a sus lectores muy lejos en el camino de la salvación, pero su arte consolará a todos con su representación de lo imposible: la plenitud que confirma la existencia, la ecclesia de los que gozan de la gracia terrestre.

Alfred J. Mac Adam

Yale University 
